\title{
Endoscopic surgical treatment of isthmocele and it's probale link with endometriosis. A 3-years retrospective review of combined laparoscopic and hysteroscopic surgery
}

\author{
Atombosoba Adokiye Ekine ${ }^{1, *}$, Fülöp István ${ }^{2}$, Rucz Árpád ${ }^{3}$, Tekse István ${ }^{4}$, Nyéky Boldizsár $^{5}$ \\ Dept. of Obstetrics and Gynecology, Robert Károly Private Hospital, Budapest, Hungary \\ *Corresponding Author: Atombosoba Adokiye Ekine \\ Email: adokin1960@gmail.com
}

Received: $12^{\text {th }}$ August, 2018

Accepted: $10^{\text {th }}$ September, 2018

\begin{abstract}
The aim, is to share our experience on the efficacy of combined laparoscopic and hysteroscopic surgical treatment of isthmocele, and the possible link with endometriosis. 28 patients with isthmocele, who underwent combined laparoscopic and hysteroscopic repair were retrospectively analysed. Presenting symptoms were; bleeding disorder, infertility, lower abdominal pain, dysmenorrhea and chronic vaginal discharge. All noticeable changes observed in the preoperative symptoms, were evaluated at 1 , 3 , and 6 months postoperatively, while fertility return within the first 24 months postoperatively was also evaluated. Average age of the patients was $36.9 \pm 4.5$, fertility return after surgery was $82.4 \%(n=14 / 17)$, post menstrual bleeding disorders was almost completely resolved in all the patients in the 1,3, and 6 months after surgery, mean bleeding duration was significantly shorter than the preoperative period 3.6 \pm 1.1 days as against $10.3 \pm 1.7$ days. There was significant resolution of the other symptoms like dysmenorrhea, chronic vaginal discharge and suprapubic pain at 6 months after surgery. Endometriosis was found in 16 (57.1\%) patients, which is remarkably high in patients who had no previous history or diagnosis of endometriosis. The overall patient satisfaction rate was $92.9 \%$ (26/28). Our experience shows that, the combined used of hysteroscopy and laparoscopy is very effective in the management of isthmocele with minimal complications. Our findings also suggests a possible link between endometriosis and isthmocele. Further large scale studies may be required to ascertain these findings.
\end{abstract}

Keywords: Endometriosis, Pelvic pain, Dysmenorrhea, Premenstrual syndrome, Abnormal uterine bleeding, Laparoscopy, Hysteroscopy, Caesarean section, Isthmocele.

\section{Introduction}

Isthmocele is an iatrogenic gynecological disorder, associated with medical conditions like; abnormal uterine bleeding, suprapubic pain, subfertility, chronic vaginal discharge, and sometimes increase in uterine rupture. It has been observed to be a longtime complication of cesarean section.

Recently, it has also become a regular medical issue in young women of reproductive age. The prevalence incidentally follows the gradual progressive tendency of cesarean section rate worldwide. ${ }^{1,2}$ However, increase in cesarean section, and improved diagnostic technology may have contributed to the increased rate of discovery. Fortunately, only some percentage of those discovered with the disorder present with symptoms suggesting, that there are cases of asymptomatic patients. ${ }^{2}$ Isthmocele has been associated with some unintended longtime sequelae such as abnormal post menstruation bleeding disorder, suprapubic pain, chronic vaginal discharge, and sub fertility affecting patient's well-being. ${ }^{2,3}$ Other fertility related consequences are scar ectopic pregnancy and uterine rupture, both life-threatening scenarios. ${ }^{4,5}$ In this study its role in secondary infertility was evaluated. Some studies have shown that, about $25-88 \%$ of patients with cesarean section, will develop uterine scar defect few months later. ${ }^{6}$ Moreover, universally acceptable guidelines for the diagnosis and treatment of uterine scar defect are still unclear. Recently, diagnostic modality such as 3-D ultrasonography, saline infusion sonography, diagnostic hysteroscopy and laparoscopy, anamnesis MRI etc. has been employed to confirm or suspect isthmocele. ${ }^{5-7}$ Treatment modalities includes, conservative medical therapy, observational approach, surgical operations such as vaginal repair, hysteroscopic repair, laparotomy repair, laparoscopic repair, and also a combined hysteroscopic-laparoscopic repair., ${ }^{8,9}$ Observational approach is employed, when isthmocele is discovered accidentally, without any obvious disturbing symptoms.

Combination of estrogen and progesterone agents, represents the conservative approach which is best useful in bleeding disorder; probable mechanism of action; includes controlling of the endometrial proliferation and improving of uterine tissues micro circulation, noneffectiveness, recurrence after withdrawal of hormones and medical contraindications could be limitations. However, a study done by Tahara et al, where all the patients with post menstrual bleeding disorder had Oral contraceptives hormonal therapy, showed that the post treatment outcome was satisfactory. ${ }^{10,11}$ "Gubbini et al, Chang et.al and Fabres et al" reported hysteroscopic approach with varying degrees of success, this procedure seems superior to hormone therapy in some cases like secondary infertility, but anterior uterine wall thinning may risk uterine rupture. . $^{3,11,12}$ While "Marotta et al and Cuilan et al" used the laparoscopic approach, they later adopted the combined surgical approach (hysteroscopylaparoscope) which indeed improved all indices of 
patient satisfaction, including return to fertility with less bladder injury etc. and eliminated the pitfall of the other previously used methods. ${ }^{13}$

\section{Materials and Methods}

The study was conducted at the Endoscopic surgical unit, department of Obstetrics and Gynecology, Robert Károly Private Hospital, Budapest, Hungary.

The study protocol was approved by the Ethical Committee of the Robert Károly Private Hospital on the 15th. January, 2017.

Using the hospital Data Base, we conducted a retrospective analysis of data relating to 34 patients with post-cesarean section isthmocele. However, only 28 agreed for surgical management, and all underwent combined hysteroscopic and laparoscopic repair except one, who opted for only hysteroscopy repair and were followed up between January 2013 and June 2016. During the setup of the diagnosis, factors considered included: (a) the history of the patient, (b) uneven distribution of the uterine wall thickness and absence of smooth area over the lower section of the myometrium at the site of the cesarean section scar; (c) presence of $\mathrm{V}$ or U shaped area of anechoic space (with or without fluid) at least $\leq 2 \mathrm{~mm}$ deep, at the site of the cesarean section scar, thinning of the myometrial wall of the anterior portion of the uterus; and (d) vascular hyperplasia and blood clots in the uterine serosa, where the defect is located, (e) none of the patient had symptoms relating to or diagnosed with endometriosis before the cesarean section(s) was performed, (f) previous incident of any form of infertility was not found in patients' medical history.

Exclusion criteria; included, congenital abdominal wall dysplasia or isthmocele as a result of other postoperative abdominal incisional hernia, previous myomectomy and patient refusal.

All the 28 patients had combined laparoscopic and hysteroscopic surgery, except one who opted for only hysteroscopic repair after counseling about the size of the isthmocele, cost of treatment and about the management options.

Laparoscopic and Hysteroscopic Surgical Procedure: The procedures were scheduled and done at the end of their menstruation (or on the tenth day for patients with menstruation lasting >8 days), under general anaesthesia, patient placed in the Trendelenburg (headdown) position. Hysteroscopic evaluation of the endometrial cavity was performed to exclude, or treat other pathologies in the cavity, and to identified the presence of isthmocele mucosal hyperplasia, which appeared partially white, to confirm the location and size of the isthmocele and its relationship with the bladder as shown in [Fig. 1]. Followed by a careful inspection of the abdominal cavity is also concluded, to rule out other pathologies, that, maybe associated with patient's problems, such as uterine fibroid, intra-abdominal adhesions, other ovarian pathologies etc. [Fig. 2 ].
Ultrasonic scalpel was used to incise the peritoneal fold over the bladder, and the bladder was pushed down to 2 $\mathrm{cm}$ below the lower edge of the isthmocele with the help of duckbill pliers as shown in [Fig. 3, 4]. Meanwhile, another surgeon or a surgical assistant was designated to use an intrauterine sound to push-up the area affected for the surgeon doing the laparoscopic manoeuvres intraabdominally.

And the orange-red light source to locate the diseased area of the lower segment of the uterus. Electric coagulation hook was used to open the isthmocele laparoscopically. The uterine isthmocele is cut in full length, the wound trimmed, and 2-0 absorbable stich used to perform full thickness suture seen in [Fig. 4, 5 and 6]. The peritoneum covering the bladder is closed after the repair uterine walls, control ultrasound by Transvaginal three-dimensional (3D) Color Doppler ultrasound and Hystero-salpingo-contrast sonography were performed to verify the uterine wall integrity 4 weeks after surgery. Monitoring: All the 28 patients were followed up postoperatively, but with differences in duration, those with mainly infertility issues were monitored for about three years, however those with other dominant symptoms like; pain, bleeding disorders were monitored for 1 to 6 months. Postoperative outcome was based on return of fertility, ultrasonographical disappearance or reduction in size of the liquid dark area of the uterine scar plus improved thickness of the serosal layer on trans vaginal 3DDoppler ultrasound and the continuous presence or absence of symptoms which was used as measures of the outcome.

Statistical Analysis were carried out with SPSS version 24 software (SPSS Inc., Chicago, IL, USA) used to analyzed the data on the checklist created for this study.

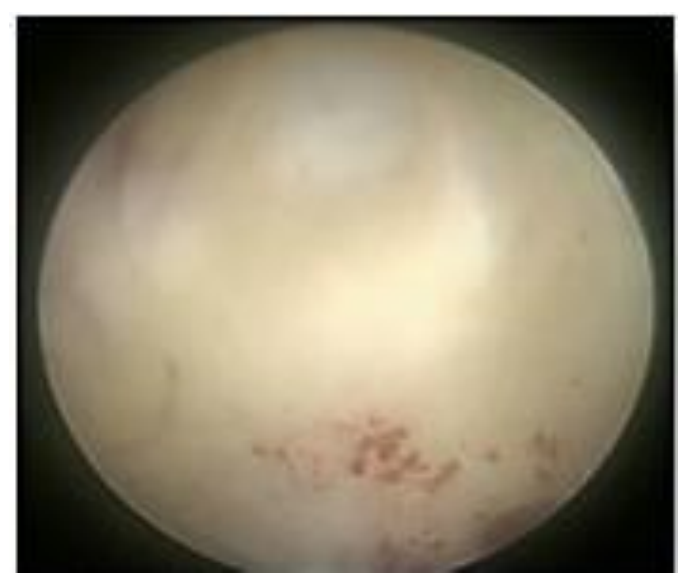

Fig. 1: Image showing the bright light site or portion where isthmocele is seen, during the hysteroscopic procedure; Endoscopic department, Robert Károly Private Hospital, Budapest, Hungary, 2016 


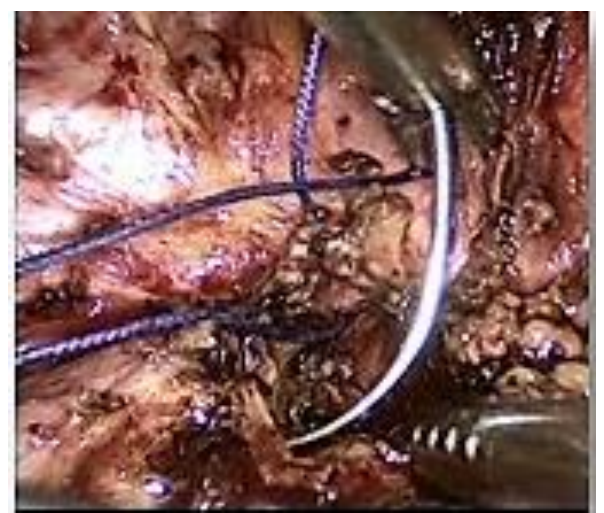

Fig. 2: Image showing adhaesions of the bladder wall,isthmocele and part of major omentum during the laparoscopic procedure; Endoscopic department, Robert Károly Private Hospital, Budapest, Hungary, 2016

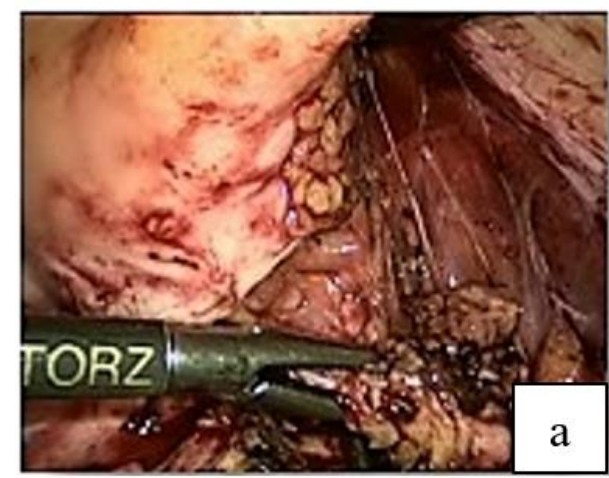

a

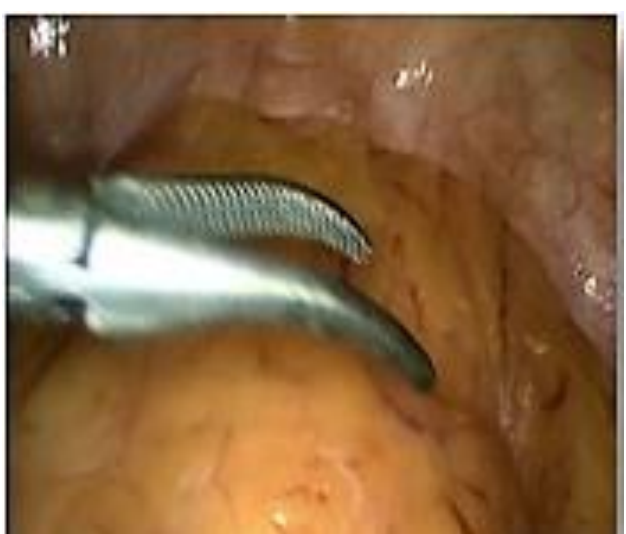

Fig. 3: Image showing the peritoneal and retrovaginal septum involvement of endometriotic leasions during the laparoscopic procedure; Endoscopic department, Robert Károly Private Hospital, Budapest, Hungary, 2016

Fig. 4: Image showing bladder walls pushed up from the site of isthmocele for about $2 \mathrm{~cm}$, during the laparoscopic procedure; Endoscopic department, Robert Károly Private Hospital, Budapest, Hungary, 2016

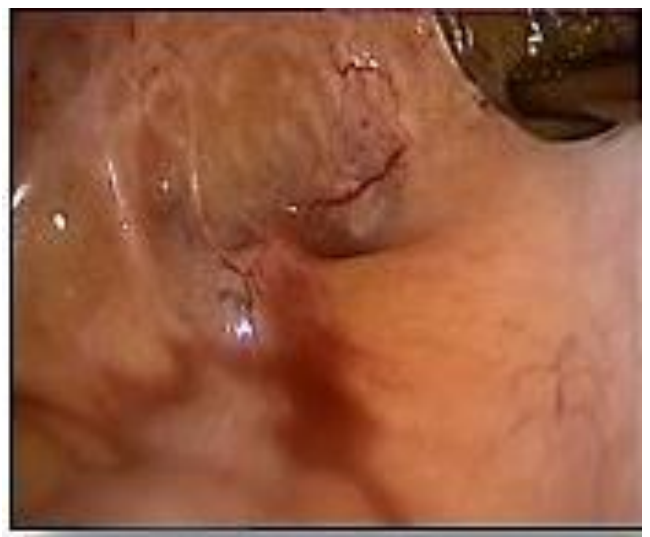

Fig. 5: image showing the cervico-uterine junction where scar tissued has been excised, during the laparoscopic procedure; Endoscopic department, Robert Károly Private Hospital, Budapest, Hungary, 2016

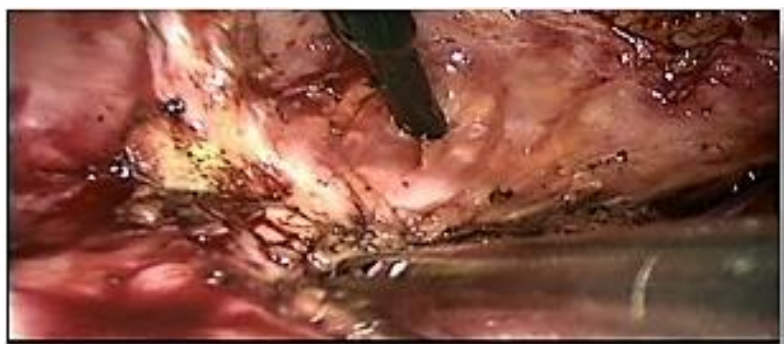

Fig. 6: Image showing the closure of the trimmed uterine wall, with a 2.0 absorbable suture, during the laparoscopic procedure; Endoscopic department, Robert Károly Private Hospital, Budapest, Hungary, 2016

\section{Results}

The mean patient age was $36.9 \pm 4.5$ years with range from 23-42 years. Of the 28 patients, 20 (71.4\%) had undergone a single previous Caesarean section delivery and 8 patients $(28.6 \%) \geq 2$ deliveries, by Caesarean sections (Table 1). A total of $25(89.3 \%)$ patients had different forms of bleeding disorders, 18 patients (64.3\%) experienced chronic menstrual pain, 13 patients $(46.4 \%)$ had recurrent vaginitis, 23 patients $(82.1 \%)$ had 
chronic supra pubic/ lower Abdominal pain, while 17 $(60.7 \%)$ patients were diagnosed with secondary infertility (Table 1).

The mean duration of bleeding was $10.3 \pm 17.9 \mathrm{std}$, the mean duration of infertility was $2.9 \pm 1$.8years, while mean duration of all symptoms including infertility was $1.2 \pm 0.41$ years (Table 1). Intraoperative findings; 15 patients $(53.6 \%)$ had to undergo lysis of pelvic adhesions, and 4 (14.3\%) had to undergo endometrial polyp resection. A total of 2 patients (7.1\%) had myoma and underwent myomectomy, which was not associated with complications such as massive hemorrhage, meanwhile endometriosis of different localization was observed in 16 patients (57.1\%) as shown in Table 2. The geometric characteristics of the isthmocele before surgery using the Hystero-salpingo-contrast sonography, Saline infusion sonography and or Doppler ultrasound data showed that; patients with scar size $(6 \times 15 \times 5 \mathrm{~mm})$ were $16(57.1 \%)$, those with scar size $(15 \times 20 \times 10 \mathrm{~mm})$ were $7(25.0 \%)$ and patients with scar size $(15 \times 25 \times 12 \mathrm{~mm})$ were $5(17.9 \%)$, while, the endometrium thickness measured among the patients with $\leq 3 \mathrm{~mm}$, were $16(57.1 \%)$, and those with endometrium thickness $\geq 3$ mm was $12(42.9 \%)$ (Table 1). Surgical records showed that, the average blood loss was $60.08 \mathrm{ml}(30-150 \mathrm{ml})$, the average operating time was $45 \mathrm{~min}$. (30-120 min.). More than, $95.7 \%(n=22 / 23)$ of the patients had remarkable relief of lower abdominal pain after the $3^{\text {rd }}$ month postsurgery (McNemar test $\mathrm{p}<0.001)$. Similar outcome was observed in those with dysmenorrhea, $94.4 \%(\mathrm{n}=17 / 18)$, and $100.0 \%$ relief recorded for post menstrual bleeding disorder $(n=25 / 25)$ and vaginal discharge $(n=13 / 13) 3$ months post-surgery in Table 3 . The mean duration of menstruation decreases drastically after the surgery to normalcy in the first three month 3.6 days \pm 1.07 days (range 3-7 days), which was statistically significant, compared to the preoperative duration (based on Wilcoxon signed rank test $p<0.001$ ) (Table 3). There was a significant reduction of all symptoms and improvement of wellbeing of patients from the first month after isthmocele surgery, as compared to before the surgery (Table 3 ). In the first 12 months after the surgery $76.5 \%(\mathrm{n}=13 / 17)$ became pregnant, while $5.9 \%$ $(n=1 / 17)$ became pregnant after between 12-24 months. There was significant $(\mathrm{p}<0.001)$ improvement in all the parameters; for those with infertility issues, or with pain (Table 4).

Table 1: Basic symptoms and clinical characteristics of patient $(n=28)$

\begin{tabular}{|l|c|c|}
\hline \multicolumn{1}{|c|}{ Symptom and patient's characteristics } & Frequency & Percent \\
\hline All symptoms associated with isthmocele & 5 & $17.9 \%$ \\
\hline Dysmenorrhea & 18 & $64.3 \%$ \\
\hline Suprapubic lower abdominal pain (LAP) & 19 & $67.3 \%$ \\
\hline Subferility (infertility) & $\begin{array}{c}2.9 \pm 1.8 \text { (range } 1.6-8.0 \\
\text { Years) } 17\end{array}$ & $60.7 \%$ \\
\hline $\begin{array}{l}\text { Post menstruation bleeding disorder/menorrhagia } \\
\text { (PMBD) }\end{array}$ & $\begin{array}{c}10.3 \pm 1.7 \text { (range } 9-17 \text { days) } \\
\text { Chronics vaginal discharge }(\mathrm{CVD})\end{array}$ & $89.3 \%$ \\
\hline History of 1 previous caesarean section & 13 & $46.4 \%$ \\
\hline History of $\geq 2$ previous caeseran section & 17 & $60.7 \%$ \\
\hline Caesarean section incision closure $($ single layer) & 11 & $39.3 \%$ \\
\hline Size of isthmocele $(\leq 6 \times 15 \times 5 \mathrm{~mm})$ & 20 & $71.4 \%$ \\
\hline Size of isthmocele $(\leq 15 \times 20 \times 10 \mathrm{~mm})$ & 16 & $57.1 \%$ \\
\hline Size of isthmocele $(\geq 15 \times 25 \times 12 \mathrm{~mm})$ & 7 & $25.0 \%$ \\
\hline Endo-myometrium thickness $(\leq 3 \mathrm{~mm})$ & 5 & $17.9 \%$ \\
\hline Endo-myometrium thickness $(\geq 3 \mathrm{~mm})$ & 16 & $57.1 \%$ \\
\hline
\end{tabular}

Table 2: Intra-operative and grsoss early clinical outcome ( $n=28)$

\begin{tabular}{|l|c|c|}
\hline \multicolumn{1}{|c|}{ Intra-operative characteristics } & Freguency & Persent \\
\hline Average duration of surgery & \multicolumn{2}{|c|}{$45.0 \mathrm{~min}$. (range 35mm-120min) } \\
Average blood loss & \multicolumn{2}{|c|}{$60.1 \mathrm{ml} \pm 20.2 \mathrm{ml}$ (range 35-150ml) } \\
\hline Endometriosis & 16 & $57.1 \%$ \\
\hline Uterine fibroid & 2 & $7.1 \%$ \\
\hline Endometrial polyp & 4 & $14.3 \%$ \\
\hline Intra abdominal adhaesion & 15 & $53.6 \%$ \\
\hline
\end{tabular}


Table 3: Post-operative follow-up outcome, and patient's well-being score $(\mathbf{n}=\mathbf{2 8})$

\begin{tabular}{|c|c|c|c|c|}
\hline \multirow[t]{2}{*}{ Symptoms } & \multicolumn{3}{|c|}{$\begin{array}{c}\text { Relief of symptoms by month after } \\
\text { surgery }\end{array}$} & \multirow{2}{*}{$\begin{array}{c}\text { Total number of patients } \\
\text { in each symptoms } \\
\text { category }\end{array}$} \\
\hline & 1st. month & 3rd. month & 6th. month & \\
\hline Dysmenorrhea & $16(88.9 \%)$ & $17(94.4 \%)$ & $18(100.0 \%)$ & 18 \\
\hline $\begin{array}{l}\text { Postmenstruation bleeding } \\
\text { disorder/menorrhagia (PMBD) } \\
\text { Duration of menstruation after surgery } \\
3.6 \pm 1.069 \text { days) }\end{array}$ & $16(84.2 \%)$ & $24(96.0 \%)$ & $25(100.0 \%)$ & 25 \\
\hline Suprapubic lower abdominal pain (LAP)* & $16(84.2 \%)$ & $18(94.7 \%)$ & $19(100.0 \%)$ & 19 \\
\hline Chronic vaginal discharge (CVD) $)^{* *}$ & $10(76.9 \%)$ & $13(100.0 \%)$ & & 13 \\
\hline
\end{tabular}

There was a significant reduction of all symptoms and improvement of well-being of patients from the first month after isthmocele surgery, as compared with before the surgery.

Mc Nemar test result $\mathrm{p}<0.001 ; * \mathrm{p}=0.001 ; * * \mathrm{p}=0.039$

Table 4: Post-operative follow-up outcome, infertility and patient's well-being score (n=17)

\begin{tabular}{|l|c|c|c|c|}
\hline \multicolumn{1}{|c|}{ Characteristics } & $\begin{array}{c}\text { Number of } \\
\text { pregnancy in } 6 \\
\text { months }\end{array}$ & $\begin{array}{c}\text { Number of pregnancy } \\
\text { in 12 months }\end{array}$ & $\begin{array}{c}\text { Number of } \\
\text { pregnancy in 24 } \\
\text { months }\end{array}$ & Frequency \\
\hline Mode of pregnancy (ART) & $1 / 17(5.9 \%)$ & $5 / 17(29.4 \%)$ & $1 / 17(5.9 \%)$ & $7 / 17(41.2 \%)$ \\
\hline $\begin{array}{l}\text { Mode of pregnancy } \\
\text { (spontaneous) }\end{array}$ & $4 / 17(23.5 \%)$ & $2 / 17(11.8 \%)$ & $1 / 17(5.9 \%)$ & $7 / 17(41.2 \%)$ \\
\hline $\begin{array}{l}\text { Total number of pregnancy } \\
\text { within 24 months post surgery } \\
\text { follow-up }\end{array}$ & & & & $14 / 17(82.4 \%)$ \\
\hline $\begin{array}{l}\text { Total number of non pregnant } \\
\text { patients after 24 months post } \\
\text { surgery }\end{array}$ & & & & $3 / 17(17.6 \%)$ \\
\hline $\begin{array}{l}\text { Total infertility patients before } \\
\text { isthmocele surgery }\end{array}$ & & & & \\
\hline
\end{tabular}

\section{Discussion}

There has been no perfectly acceptable explanation to all the issues raised about isthmocele. Why it occurs in some cases, differences in the symptomatology, criteria for diagnosis, absolute risk factors, correlation between size of scar, medical implication, and duration of onset from the cesarean section to date. However, the uterus, like every other tissue, when under stress and tension may be subjected to deformity, protrusion or rupture, depending on the nature and place. Therefore, this phenomenon could also be experienced or be applicable to the tissues of the myometrium and endometrium as they are not exceptions. When this tissue deformity occurs, usually at the weakest site of the uterus, that is the lower uterine segment, it is referred to as isthmocele (scar defect, niche, diverticulum etc.). ${ }^{10}$ Rarely, we do come across some cases of congenital uterine diverticulum, which is usually associated with congenital renal dysplasia. ${ }^{11-13}$ Complications of Casarean section, may arise as a result of poor alignment and single uterine closure techniques, poor wound healing, dysplastic endometrial capillary dilatation, and inflammatory tissue infiltration contributing to the increased risk of the expansion of the uterine incision. ${ }^{14,15}$ Despite, little symptomatology of this iatrogenic disorder, none of the symptoms (postmenstruation bleeding disorder, dysmenorrhea, lower abdominal supra pubic pains, chronic vaginal discharge etc.) are hundred percent specific to the isthmocele. ${ }^{16,17}$ However, post menstrual bleeding disorder seems to be the only likely symptom, that may point towards possibility of isthmocele, whereas, most of the other symptoms are not specific to isthmocele alone. Evidently, the clinical manifestations are not so obvious in most cases and may require the use of ultrasound examination to make a diagnosis of isthmocele. ${ }^{17,18}$ Apart from the regular nonspecific symptoms of isthmocele, it also carries the danger of uterine rupture, scar ectopic pregnancy, placenta acreta etc., which can all lead to poor feto-maternal outcome in a given pregnancy. The tendency of this phenomena is increasing as the rate of cesarean section globally has grown rapidly in the past $2-3$ decades from about $\leq 25$ $\geq 55 \%$.

The current more preferred single suture uterine closure, may have also played a vital role in the increased incidence of the isthmocele. ${ }^{15,16,18}$ Management of isthmocele, largely depend on patient preference, age, dominating symptoms, scar characteristics (size), patient needs, and surgical skills of the operating team.

The frequently adopted operational techniques are the vaginal repair, hysteroscopy, laparoscopy, and the combined use of hysteroscopy and laparoscopy. Many literatures have demonstrated that reconstruction of the 
scared uterus, undoubtedly improves the patient's general well-being, and in most cases resulted in the return of fertility. ${ }^{3,711,15}$ However, all the management models so far employed have their shortcomings; like in the vaginal repair, lack of proper accessibility of the isthmocele, hysteroscopy, with improper repair as a result of poor orientation, depth and size of scar, while with laparoscopy alone has its handicaps like poor visualization and consequently low accuracy of diverticular orientation.7,18,19 Based on the various shortcomings of the methods, a combined approach was applied in our center based on the symptoms; a combined hysteroscopy and laparoscopy repair was adopted. It was found to be safe, and more effective, as it provides superior visualization of the scar, which ultimately improves the orientation and a more accurate repair. As evident by the postoperative outcome of this study, the fertility return was $82.4 \%(n=14 / 17)$ after 24 months post-surgery, was similar to a recent study, which reported significant clinical improvement in 14 patients with uterine incision diverticulum who underwent combined hysteroscopic and laparoscopic repair by Cuilan $\mathrm{Li}$ et $\mathrm{al}^{11}$ and others. ${ }^{17}$ Significant reduction or complete reversal of symptoms was also recorded in those with post menstruation bleeding disorder, $100.0 \%$ $(\mathrm{n}=25 / 25) 6$ months after post-surgery, as all patients returned to normal menstruation cycles, similar to the outcome of a study conducted by Changdong $\mathrm{Li}$ et al., and Cuilan $\mathrm{Li}$ et al, on patients with symptoms of diverticulum of the uterine scar. ${ }^{8,20}$ A significant reduction or alleviation of symptoms was recorded after the first month's post-surgery. Great improvement was recorded in all the patients, both symptoms and general patient's well-being among all the indices under review, as we achieved almost complete disappearance of dysmenorrhea, lower abdominal pain (supra pubic pain) and complete resolve of vaginal discharge after the 6 months post-surgery. The postoperative success rate in the first 3 months was, $94.7 \%$ for suprapubic lower abdominal pain $100.0 \%$ for vaginal discharge, $94.4 \%$ for dysmenorrhea, and $96.0 \%$ for post menstrual belled disorder better or similar to results from other studies. ${ }^{11,12}$ The other advantage with the combined approach is the possibility of eliminating or reducing complication during the surgery, such as pushing down the bladder during laparoscopy to fully expose the scar, thereby minimizing the possible bladder injury. ${ }^{11,12,17}$ The laparoscopy also helped to identify other intraabdominal abnormalities, which were treated to give the patient relief from other medical conditions, like endometriosis, adhesion, ovarian cyst, fibroid etc. ${ }^{11,20}$ While the presence of fibroid was accidental and statistically not significant, intra-abdominal adhesion was statistically significant with, 53.6\% ( $n=15 / 28)$ which is an expected postoperative complication of every abdominal surgery in [Fig. 2]. Unlike intraabdominal adhesion, endometriosis is not expected to be a possible late complication of abdominal surgery; including cesarean section. However, the involvement of endometriosis with American Society for Reproductive Medicine classification stage ranging between stage 1-3 in this group of patients, $57.1 \%(n=16 / 28)$ as shown in Figure 3. This occurrence could not just be assumed an accidental phenomenon. This therefore, has triggered doubts and raised questions about the correlation and possible link between Caesarean section and or the isthmocele as among one of the contributing factors in the onset of endometriosis in some cases.

Hypothetically, this onset could possibly arise from either the transplantation theory; that is adenomyotic lesions transportation via lymphoenous or hematogenous embolization or by direct extension of adenomyotic nodules through the thin uterine walls by Carmen Maccagnano et $\mathrm{al}^{20-22}$ or by iatrogenic theory, were there is direct dissemination of endometrial cells, aided by curettage during the cesarean section, or poor alignment tissues during closure by Carmen Maccagnano et al. ${ }^{23,24}$ Although the possible mechanism is not clear, however the occurrence could be either by direct implantation or through dissemination through the isthmocele, due to long stagnation of the menstruation fluid. This phenomenon could strongly suggest and support the implantation theory of the endometriosis [Fig. 3]. However, large and comprehensive study will be required to fully support or discard the hypothesis. Meanwhile the hysteroscopy aided surgery is not just by providing the use of an orange-red light source for guidance to accurately determine the location and extent of the isthmocele, and after resection of the isthmocele and suture, it was also used to confirm the integrity of the surgery and resolution of intrauterine pathologies, like polyps, synechia etc. This we were able to achieve as none of our patients had any severe complication as a result of the surgery. Although the combined technique improves the patient's health indices, it demands higher professionalism, financial implication than the single methods. Conclusively, we realized that the application of the combined hysteroscopy, and laparoscopy greatly improved fertility rate of those with sub fertility, it had also raised some questions about the role of cesarean section scar defect or the cesarean section on the onset of endometriosis, as more than $1 / 2$ of the patients were diagnosed of the disease, which is remarkably high in patients without previous history of endometriosis. More so, it also has appeared to improve in all the indices of the general patient's well-being. It also provides better safety to patients, with very little complications. However, due to our small sample size, it could be too early to draw a link between the isthmocele and the endometriosis. A larger multicenter study may provide better information in this regard.

\section{Competing Interests}

The authors declare that there are no competing interests regarding the publication of this paper. 


\section{Acknowledgement}

We thank all the nurses and administrative staff of the endoscopic department of the hospital, for the data collection.

\section{Disclosure Statement}

The authors report no conflicts of interest. The authors alone are responsible for the content and writing of the article. None of the authors have relevant financial, political, religious or personal interest linked to the subject of this article.

\section{Ethics Approval}

Written informed consent was obtained from the Róbert Károly Magán hospital ethical committee, who allowed the retrieval of patients' data from the hospital medical archives for this study.

\section{References}

1. WHO, HRP. WHO statement on caesarean section rates. Executive summary. April 2015, WHO/RHR/15.02, 1-8

2. A. P. Betr'an, M. Merialdi, J. A. Lauer. Rates of caesarean section: analysis of global, regional and national estimates. Paediatric and Perinatal Epidemiology, 2007;21(2):98-113.

3. Gubbini G, Centini G, Nascetti D. Surgical hysteroscopic treatment of cesarean-induced isthmocele in restoring fertility: prospective study. J Minim Invasive Gynecol. 2011;18(2):234-7. doi: 10.1016/j.jmig.2010.10.011.

4. Atef Darwish. Microsurgical Cesarean Section, http://dx.doi.org/10.5772/67123

5. A. J. M. Bij deVaate, L. F. vander Voet, O. Naji. Prevalence, potential risk factors for development and symptoms related to the presence of uterine niches following Cesarean section: systematic review. Ultrasound in Obstetrics and Gynecology. 2014;43(4):372-382.

6. Fabres C, Aviles G, De La Jara C, Escalona J, Muñoz JF, Mackenna A. The cesarean delivery scar pouch: clinical implications and diagnostic correlation between transvaginal sonography and hysteroscopy. J Ultrasound Med. 2003;22:695-700.

7. P. Florio, M. Filippeschi, I. Moncini, E. Marra, M. Franchini, and G. Gubbini. Hysteroscopic treatment of the cesarean-induced isthmocele in restoring infertility. Current Opinion in Obstetrics and Gynecology. 2012;24(3):180-186.

8. Pasquale Florio, Giampiero Gubbini, Elena Marra. A retrospective case-control study comparing hysteroscopic resection versus hormonal modulation in treating menstrual disorders due to isthmocele Gynecological Endocrinology. 2011;27(6).

9. Tahara M, Shimizu T, Shimoura H. Preliminary report of treatment with oral contraceptive pills for intermenstrual vaginal bleeding secondary to a cesarean section scar. Fertil Steril. 2006;86(2):477-79.

10. Fabres C, Arriagada P, Fernández C, Mackenna A, Zegers F, Fernández E. Surgical treatment and follow-up of women with intermenstrual bleeding due to cesarean section scar defect. J Minim Invasive Gynecol. 2005; $12: 25-8$

11. Cuilan Li, 1 Shiyan Tang, 1 Xingcheng Gao. Efficacy of Combined Laparoscopic and Hysteroscopic Repair of Post-Cesarean Section Uterine Diverticulum: A Retrospective Analysis; Bio Med Research International.
2016 (2016), Article ID 1765624, 6 pages http://dx.doi.org/10.1155/2016/1765624

12. Changdong Li, Yinshu Guo, Yun Liu, Jiumei Cheng, Weiyuan Zhang. Hysteroscopic and laparoscopic management of uterine defects on previous cesarean delivery scars. Journal of Perinatal Medicine, ISSN (Online) 1619-3997, ISSN (Print) 0300-5577, DOI: https://doi.org/10.1515/jpm-2013-0081

13. L. F. van der Voet, A. M. Bij de Vaate, S. Veersema, H. A. M. Brölmann, and J. A. F. Huirne, "Long-term complications of caesarean section. The niche in the scar: a prospective cohort study on niche prevalence and its relation to abnormal uterine bleeding," $B J O G$, 2014;121(2):236-244.

14. Wang CB, Chiu WW, Lee CY, Sun YL, Lin YH, Tseng CJ. Cesarean scar defect: correlation between cesarean section number, defect size, clinical symptoms and uterine position. Ultrasound Obstet Gynecol. 2009;34:85-9.

15. Giampietro Gubbini, Gabriele Centini, Daniela Nascetti., Surgical Hysteroscopic Treatment of Cesarean-Induced Isthmocelein Restoring Fertility: Prospective Study. The Journal of Minimally Invasive Gynaecology. doi:10.1016/j.jmig.2010.10.011

16. Enkin MW, Wilkinson C. Single versus two-layer suturing for closing the uterine incision at caesarean section. Cochrane Database Syst Rev. 2000; 2:CD000192.

17. C. Li, Y. Guo, Y. Liu, J. Cheng, and W. Zhang, "Hysteroscopic and laparoscopic management of uterine defects on previous cesarean delivery scars. Journal of Perinatal Medicine. 2014;42(3)363-370.

18. M.-L.Marotta, J. Donnez, J. Squifflet, P. Jadoul, N. Darii, and O. Donnez, "Laparoscopic repair of post-cesarean section uterine scar defects diagnosed in nonpregnant women." Journal of Minimally Invasive Gynecology. 2013;20(3):386-391.

19. Gubbini G, Casadio P, Marra E. Resectoscopic correction of the "isthmocele" in women with postmenstrual abnormal uterine bleeding and secondary infertility. $J$ Minim Invasive Gynecol. 2008;15:172-5.

20. Deger A, Yaylak F, Bayhan Z. Endometriosis in the Surgical Scar Tissue after Caesarean Section. Ann Clin Pathol. 2014;2(2):1022.

21. Maccagnano C, Pellucini F, Rocchini L, Ghezzi M, Scattoni V, Montorsi F, Rigatti P, Colombo R. diagnosis and treatment of bladder endometriosis: state of the art. Urol Int. 2012;89:249-258. DOI: 10.1159/000339519

22. Donnez J, Spada F, Squifflet J, Nisolle M: Bladder endometriosis must be considered as bladder adenomyosis. Fertil Steril. 2000;74:1175-1181.

23. Vercellini P, Busacca M, Aimi G, Bianchi S, Frontino G, Crosignani PG: Lateral distribution of recurrent ovarian endometriotic cysts. Fertil Steril. 2002;77:848-849.

24. Donnez J, Van Langendonckt A, Casanas-Roux F, Van Gossum JP, Pirard C, Jadoul P, Squifflet J, Smets M: Current thinking on the pathogenesis of endometriosis. Gynecol Obstet Invest. 2002;54(suppl 1):52-62.

How to cite this article: Ekine A. A, István F, Árpád R, István T, Boldizsár N. Endoscopic surgical treatment of isthmocele and it's probale link with endometriosis. A 3-years retrospective review of combined laparoscopic and hysteroscopic surgery. Indian J Obstet Gynecol Res. 2018;5(4):458-464. 